\title{
Effects of Implicit Power Motivation on Men's and Women's Implicit Learning and Testosterone Changes After Social Victory or Defeat
}

\author{
Oliver C. Schultheiss, Michelle M. Wirth, Cynthia M. Torges, Joyce S. Pang, \\ Mark A. Villacorta, and Kathryn M. Welsh \\ University of Michigan
}

\begin{abstract}
Two studies examined interactions of implicit power motivation and experimentally varied victory or defeat in a contest on implicit learning of a visuomotor sequence associated with the contest outcome and changes in testosterone and self-reported affect. In men and women, power motivation predicted enhanced learning (sequence-execution accuracy) after a victory and impaired learning after a defeat. In men, power motivation predicted testosterone increases among winners and decreases among losers, and testosterone decreases mediated the negative effect of power motivation on learning in losers. In women, power motivation predicted postcontest testosterone increases, particularly among losers. In both men and women, self-reported affective states were influenced only by contest outcome and were unrelated to participants' testosterone changes or implicit learning.
\end{abstract}

The implicit power motive is defined as a recurrent concern to have impact on others or the world at large (Winter, 1973). The attribute implicit reflects the pervasive finding that measures of power motivation based on content coding of imaginative stories that individuals tell about picture cues show little overlap with questionnaire measures that tap into people's consciously held views of themselves as being seekers of power and dominance (cf. McClelland, 1980; McClelland, Koestner, \& Weinberger, 1989; Schultheiss \& Brunstein, 2001). According to McClelland and his colleagues (McClelland et al., 1989; Weinberger \& McClelland, 1990), the power motive, like other motive dispositions, is based on a natural incentive whose attainment elicits pleasurable affect, thereby reinforcing behavior that was instrumental in obtaining it. In the case of the power motive, pleasure is derived from having impact; in other words, people high in power motivation are more likely than people low in power motivation to show behaviors aimed at impact because they have learned that these behaviors lead to a pleasurable outcome.

So far, however, the evidence for a reinforcing effect of impact experiences in the context of power motivation is circumstantial. McClelland and Pilon (1983) found that individuals whose aggressive and sexual behaviors had not been restrained by parental intervention in early childhood grew up to be high in power

Oliver C. Schultheiss, Michelle M. Wirth, Cynthia M. Torges, Joyce S. Pang, Mark A. Villacorta, and Kathryn M. Welsh, Department of Psychology, University of Michigan.

This research was supported by National Institute of Mental Health Grant R03 MH63069-01/02. We thank Albert Bertram for his assistance with synchronizing the computers and his help with data collection; Brooke Reinbold, Justin Heinze, and Nicolette Jones for their help with data collection; and Rachael Seidler for helpful comments and suggestions on the implicit learning aspects of the present research.

Correspondence concerning this article should be addressed to Oliver C. Schultheiss, Department of Psychology, University of Michigan, 525 East University Avenue, Ann Arbor, MI 48109-1109. E-mail: oschult@ umich.edu motivation as adults. Although this finding suggests that learning processes are involved in the development of the power motive, they are correlational and can only point to a facilitating role of unrestrained impact experiences in the development of power motivation. They provide no direct clue as to whether having impact actually reinforces behavior in power-motivated individuals. On the other hand, power-motivated individuals are known to engage in many behaviors aimed at having impact on others or the world at large, which include aggression (Mason \& Blankenship, 1987; Winter, 1973), as well as gambling (Hirschowitz \& Nell, 1983), risk taking (McClelland \& Watson, 1973), persuading others (Schultheiss \& Brunstein, 2002), and high-status possessions collecting (McClelland, 1975; Winter, 1973). For instance, powermotivated individuals speak fluently, raise their eyebrows often, and gesture frequently when trying to persuade another person. All three behaviors convey a sense of competence and thus make an impression on the observer (Schultheiss \& Brunstein, 2002). Presumably, power-motivated individuals are not born with these behaviors but acquire them because they are instrumental for being persuasive and, thus, for having impact on others. Direct evidence that would highlight the process by which they acquire such behaviors is lacking, however.

McClelland (1987) has also speculated that norepinephrine (NE), a neurotransmitter that is released during power motivation arousal (see McClelland, 1982, 1989), represents the biological substrate of the rewarding impact experience. However, the idea that NE is directly involved in brain reward receives little support from the biopsychological literature (see Rolls, 1999, for a summary). Still, the possibility remains that some other transmitters or hormones may be specifically associated with the pleasurable experience of having impact.

Our present research therefore has two main goals. First, we wanted to study whether in power-motivated individuals an impact experience in fact reinforces behavior that precedes it and, extending on this, whether failure to have impact inhibits the behavior leading to it. Second, we wanted to test whether power motivation reward is associated with an increase of the gonadal steroid tes- 
tosterone (T), whose association with behavioral measures of aggression and dominance is well documented in men (Mazur \& Booth, 1998) and which in animal studies has been found to have reinforcing effects on behavior (e.g., Frye, Rhodes, Rosellini, \& Svare, 2002). Conversely, we expected impact failure to be associated with a $\mathrm{T}$ decrease in power-motivated individuals. In addition, we wanted to explore to what extent power motivation reward or frustration is reflected in individuals' subjective affective experiences.

In the development of our research hypotheses, we were guided by findings reported by Schultheiss and Rohde (2002; see also Schultheiss, Campbell, \& McClelland, 1999). These researchers had pairs of German men compete on several rounds of a contest and experimentally varied the contest's outcome so that one participant won and the other lost by a considerable margin. Instrumental learning was assessed with a paper-and-pencil task on which participants competed during the contest that required them to connect consecutive numbers arranged in a maze-like matrix as quickly as possible. Half of the forms of this task featured a repeating visuomotor pattern that could be learned, whereas the other half did not. Assessment of participants' postcontest performance on this task revealed not only that they did have a learning advantage on the patterned forms relative to the unpatterned forms, but also that the magnitude of their learning gains depended on both the contest outcome and their power motivation levels, which were assessed with a picture story exercise (PSE) before the contest. Among winners, the power motive was a strong positive predictor of implicit learning; among losers, it was a strong negative predictor. In other words, power-motivated winners showed signs of having been reinforced in what they were doing during the contest by defeating their opponent, whereas power-motivated losers showed signs of avoiding a behavior that had led to their defeat. Notably, participants were not aware of the fact that the number-connection task featured a repeating, predictable pattern, and instrumental learning had therefore occurred without their conscious awareness or intention.

Schultheiss and Rohde (2002) also measured participants' salivary $\mathrm{T}$ levels before and after the contest and found that powermotivated winners registered a significant $\mathrm{T}$ increase 20 -min postcontest (but not immediately or $40 \mathrm{~min}$ after the contest), whereas power-motivated losers showed a nonsignificant $\mathrm{T}$ decrease. Schultheiss and Rohde also found that $\mathrm{T}$ increases 20-min postcontest were correlated with better implicit learning and demonstrated that the enhanced learning among power-motivated winners was statistically mediated by their increased $\mathrm{T}$ levels, a finding that suggests that $\mathrm{T}$ may be a hormone associated with power motivation reward.

Although Schultheiss and Rohde's (2002) findings provide some initial evidence for the ideas that power motivation shapes behavior through a process of nonconscious instrumental learning and power-driven reinforcement effects may be mediated by rewarding effects of $\mathrm{T}$, the study leaves open a number of important issues. First, it is the only study so far to document processes of reward and reinforcement in power motivation. The validity of the idea that power motivation scales the reinforcement value of impact experiences (or the punishment value of a social defeat) therefore needs to be bolstered by replication of Schultheiss and Rohde's findings.
Second, the validity of the impact-as-power-reward hypothesis also needs to be established for women, whose power motive is similar to men's in terms of its assertive-aggressive behavioral outlets (Stewart \& Chester, 1982; Winter, 1988). It is particularly important to examine the role of $\mathrm{T}$ in female power motivation, because laboratory and field studies in which women's hormonal responses to winning or losing a competition were assessed have, so far, yielded null findings (e.g., Bateup, Booth, Shirtcliff, \& Granger, 2002; Mazur, Susman, \& Edelbrock, 1997; Rejeski, Parker, Gagne, \& Koritnik, 1990), prompting Mazur and Booth (1998) to conclude that effects of competition on T are specific to men. Note, however, that in all previous competition studies, the effects of winning and losing on women's $\mathrm{T}$ changes have been tested without taking women's power motive into account, leaving open the possibility that this personality variable moderates women's hormonal responses to competition.

Third, Schultheiss and Rohde (2002) used a novel paper-andpencil measure of implicit procedural learning whose validity and convergence with more established implicit learning tasks has yet to be evaluated. It is therefore unclear whether these findings are specific to their implicit learning task or can also be obtained with procedural learning tasks more commonly used in cognitive psychology.

Fourth, and finally, it is unclear whether and to what extent subjective affective responses to winning or losing a contest reflect differences in the reward magnitude of having impact in low- and high-power individuals. Do high-power individuals subjectively experience a social victory as more pleasurable and a social defeat as more frustrating than low-power individuals do? Is the magnitude of mood changes associated with individuals' implicit learning gains or $\mathrm{T}$ changes?

\section{Present Research}

In the present research, we addressed these issues by using Schultheiss and Rohde's (2002) contest paradigm in a study with male participants (Study 1) and in a study with female participants (Study 2). In both studies, we measured participants' power motive with a PSE, used a personal computer (PC) to conduct a serial response task (SRT) to assess implicit learning gains after the contest, collected saliva samples from participants before and after the contest to determine contest-induced changes in $\mathrm{T}$, and measured participants' subjective hedonic responses to the contest outcome. The following three hypotheses guided our analyses.

\section{Instrumental-Learning Hypothesis}

On the basis of the idea that rewards and punishments have positive and negative reinforcing effects on behavior, we predicted that individuals high in power motivation, but not individuals low in power motivation, would show enhanced learning of a fixed visuomotor sequence on the SRT during the contest if they beat their opponent and thus had impact on her or him, which we expected to be rewarding for them. We predicted impaired learning of the sequence if high-power motivation individuals were defeated by their opponent and thus failed to have impact, which we expected to be aversive for them. In research on implicit learning, researchers can differentiate specific learning gains from general performance changes by comparing individuals' performance on a 
fixed sequence to their performance on random sequences. Sequence knowledge on the fixed sequence can be used to anticipate stimuli and prepare responses, whereas sequence knowledge cannot be applied to this end on random sequences. We examined the validity of the instrumental-learning hypothesis by assessing two correlated but functionally distinct aspects of sequence learning (cf. Feeney, Howard, \& Howard, 2002; Waber et al., 2003): accuracy and speed of the execution of the fixed visuomotor sequence. Our own research suggests that sequence-execution accuracy is a more sensitive measure of reinforcement effects than execution speed (Schultheiss, Pang, Torges, Wirth, \& Treynor, in press). For instance, we found that power-motivated individuals showed particularly enhanced learning of sequences followed by the presentation of faces expressing surprise when the accuracy criterion was examined, but not when the speed criterion was used. In keeping with these observations, we expected the instrumentallearning hypothesis to be more valid for sequence-execution accuracy than for sequence-execution speed.

\section{T-Response Hypothesis}

We predicted that in men, high levels of power motivation would be associated with a $\mathrm{T}$ increase after a victory and a $\mathrm{T}$ decrease after a defeat. This prediction is based on Schultheiss and Rohde's (2002) findings (see also Schultheiss et al., 1999) and is consistent with Mazur's (1985; Mazur \& Booth, 1998) model of a reciprocal relationship between $\mathrm{T}$ and dominance contest outcomes. According to this model, $\mathrm{T}$ and behavior are related in two ways. First, high or rising levels of $\mathrm{T}$ make a person more motivated to seek dominance over others; thus, $\mathrm{T}$ primes the person for assertive behavior. Second, outcomes of dominance-related person-environment transactions feed back into an individual's $\mathrm{T}$ levels such that after a dominance success, $\mathrm{T}$ rises and, after a defeat, $\mathrm{T}$ falls. Outcome-induced $\mathrm{T}$ changes determine in turn whether an individual will continue to strive for dominance (i.e., in the presence of victory-induced $\mathrm{T}$ increases) or abandon further attempts at dominating others (i.e., in the presence of defeatinduced $\mathrm{T}$ decreases). ${ }^{1}$ Mazur (1985) also speculated that outcome-induced $\mathrm{T}$ changes have a reinforcing effect on behavior, with dominant behaviors being reinforced by victory-induced $\mathrm{T}$ increases and inhibited by defeat-induced $\mathrm{T}$ decreases. It is notable in this context that not only has the power motive been found to predict men's $\mathrm{T}$ responses to winning or losing a contest, T-associated learning of instrumental behavior (Schultheiss \& Rohde, 2002), and thus the behavioral feedback component of Mazur's model, but research has also revealed that in men, high levels of power motivation are associated with high baseline levels of $\mathrm{T}$, which may prime power-motivated individuals to engage in assertive behaviors (Schultheiss et al., 1999; Schultheiss, Dargel, \& Rohde, 2003). In other words, men high in power motivation show evidence for a role of $\mathrm{T}$ as a primer of dominant behavior and as an indicator of its success.

We agree with Mazur and Booth (1998) that the validity of Mazur's model is not as well established for women as it is for men. Nevertheless, research suggests that in women, as in men, $\mathrm{T}$ is associated with dominance and aggression. For instance, Dabbs and his collaborators reported that in female prison inmates, those with a more extensive record of aggressive behavior are higher in $\mathrm{T}$ (Dabbs \& Hargrove, 1997) and that among adolescents, high-T girls are just as prone as high-T boys to engage in antisocial, rebellious behavior (Banks \& Dabbs, 1996). Moreover, in a carefully designed double-blind study, van Honk et al. (2001) showed that women treated with $\mathrm{T}$ showed a stronger cardiovascular response than women treated with placebo to perceived facial expressions of anger - a dominance signal (cf. Knutson, 1996) but not to happy or neutral faces. Research also shows that high-T women are more likely than low-T women to work in high-status occupations (e.g., Dabbs, Alford, \& Fielden, 1998; Purifoy \& Koopmans, 1979) and to respond to status threats (Josephs, Newman, Brown, \& Beer, 2003). Thus, high-T women show many of the hallmarks of individuals endowed with a strong power motive (cf. McClelland, 1987; Winter, 1996), and we therefore predict that women high in power motivation will show a stronger $\mathrm{T}$ response to the contest than women low in power motivation. However, in the absence of any documented $\mathrm{T}$ differences in female winners and losers of a contest, and also taking into account that the physiology of $\mathrm{T}$ release in females differs significantly from that in males (cf. Sapolsky, 1987), we feel it would be premature at this point to predict the specific direction of female $\mathrm{T}$ changes induced by winning or losing a dominance contest.

\section{Hedonic-Change Hypothesis}

On the basis of past research showing that people report strong affective responses to winning or losing real games (e.g., G. V. Wilson \& Kerr, 1999) or staged contests in the laboratory (e.g., Gladue, Boechler, \& McCaul, 1989; McCaul, Gladue, \& Joppa, 1992), we expected winners to transiently experience considerably more satisfaction and happiness after the contest than losers. In addition, we expected participants' power motive to moderate this effect. Brunstein, Schultheiss, and Grässmann (1998) reported that individuals are happier when they realize goals that satisfy their underlying motive dispositions than when they realize goals that do not meet their motivational needs, and they are more dissatisfied when they fail to attain motive-congruent goals than when they fail to attain motive-incongruent goals. We therefore predicted that winners' and losers' affective responses to the contest would be potentiated by their power motive: Individuals with a strong power motive should be more satisfied with a victory and more dissatisfied with a defeat than individuals with a weak power motive.

\section{Study 1}

We first tested our hypotheses in a sample of young male adults, for whom previous research had established the effects of implicit power motivation and winning or losing a dominance contest on implicit learning and T changes (Schultheiss et al., 1999; Schultheiss \& Rohde, 2002). To assess implicit learning, we adapted a

\footnotetext{
${ }^{1}$ Mazur (1985) did not specify how quickly defeat-induced $\mathrm{T}$ decreases will make the individual accept his or her lower social rank, and it is possible that an individual's initial response to a defeat is characterized by reactance and vigorous attempts to regain dominance (e.g., Klinger, 1975; Wortman \& Brehm, 1975). However, to the extent that an individual is defeated repeatedly or decisively, a decrease in aggression and selfassertion mediated by reduced $\mathrm{T}$ may protect the individual from wasting energy on or getting injured during further dominance fights.
} 
task developed by Curran (1997) on which participants worked on random and fixed visuomotor sequences in alternating order before, during, and after the contest. Learning gains were assessed after the contest, that is, after execution of the fixed visuomotor sequence had become associated with either a victory or a defeat. Participants' subjective affective responses to the contest were measured with the hedonic tone scale by Matthews, Jones, and Chamberlain (1990) that, according to the authors, is designed to assess motivational gratification and frustration.

\section{Method}

Participants. From September 2001 to February 2002, 104 individuals participated in sessions scheduled between 9 a.m. and 5 p.m. Because of fluctuations in the power supply to the testing room, the contest phase was prematurely aborted in four pairs of participants, and their data were discarded. Because of a technical error, another participant was not administered the PSE, and his data were also removed from the sample. The men remaining in the sample $(N=95)$ were 19.67 years old on average $(S D=$ 2.13) and enrolled as undergraduate and graduate students at the University of Michigan. Psychology majors were not admitted to the study.

Design. The study had a Condition $\times$ Power Motive design. Condition was varied by having 1 participant in each dyad win $(n=48)$ and the other lose $(n=47)$ a contest. Men were randomly assigned to conditions. Their power motive levels were assessed with a PSE. Dependent variables were changes in hedonic tone, $\mathrm{T}$, and implicit learning.

Procedure. All materials were presented on the computer and all responses entered on the computer keyboard, with the exception of the PSE, for which participants wrote stories on paper, and the SRT, for which participants used a four-key keypad for response registration. All programming was done using the Experimental Run Time System software by Berisoft Cooperation (Frankfurt, Germany). Sessions were run by a single male or female experimenter and consisted of a precontest, a contest, and a postcontest phase. In the precontest phase, participants provided a saliva sample (T1, at $0 \mathrm{~min}$ ), then completed a PSE, several questionnaires, and a precontest SRT. Next, the experimenter announced that participants would compete against each other in a contest based on the SRT. Participants then provided a second saliva sample (T2, at $52 \mathrm{~min}$ ), listened to a tape-recorded goal imagery exercise vividly describing the course of the ensuing contest from the winner's perspective (this was done to ensure that participants' power motive became adequately engaged in the pursuit of the experimenter-assigned goal of trying to beat their opponents on the SRT; cf. Schultheiss, 2001), and provided a third saliva sample (T3, at 64 min) while they reported their precontest affective state.

During the contest phase, participants competed against each other on 10 rounds of the SRT, with their PCs synchronized. The experimenter explained to them that after each round, the PCs would calculate their performance scores based on their speed and accuracy on the SRT and then compare their results to determine the winner of a round. Each round started with a screen announcing the round number, followed by a countdown. Participants then worked on the SRT for $50 \mathrm{~s}$. After that, they saw a black screen featuring the words "Calculating and comparing scores. .." for $2 \mathrm{~s}$, followed by either a green screen with the words "You have won this round" and accompanied by a low-volume jubilant jingle or a red screen with the words "You have lost this round" and accompanied by a low-volume, low-frequency snarling tone for $2 \mathrm{~s}$, followed by a blank screen that retained the color of the feedback screen $(3 \mathrm{~s})$. Participants in the winning condition won all rounds except for the second and the fifth, and participants in the losing condition correspondingly lost all rounds except for the second and the fifth.

At the beginning of the postcontest phase, participants collected a fourth saliva sample (T4, at $78 \mathrm{~min}$ ) while completing the affect measure (immediately after the contest), then worked on another task unrelated to the results reported below, and provided a fifth saliva sample (T5, at $93 \mathrm{~min}$ ) while reporting on their affect (15 min postcontest). Next, participants completed a postcontest SRT, an implicit learning awareness test, and provided a final saliva sample (T6, at $108 \mathrm{~min}$ ) and affect report (30 min postcontest). Finally, they completed a background-data questionnaire and a suspicion check. They were fully debriefed about the hypotheses underlying the study and the manipulations used and paid $\$ 25$ for their participation

Implicit power motive. Implicit power motivation was assessed by having participants write imaginative stories about five pictures: ship captain, bicycle race, boxer, women in laboratory, and trapeze artists. With the exception of bicycle race, which was used for the first time here to capture power motivation imagery in response to male competition cues, all pictures have been published and used in previous research (McClelland, 1975; McClelland \& Steele, 1972; Smith, 1992). Participants first viewed each picture for $10 \mathrm{~s}$ and then had $5 \mathrm{~min}$ to write a story. Stories were later coded for motivational imagery by a trained scorer using Winter's (1973) Revised Power Motive Scoring System. According to the manual, power imagery is scored whenever a story character expresses a power concern through strong forceful actions; provides unsolicited help, support, or advice; tries to control or regulate others' behavior; tries to influence, persuade, bribe, or argue with another person; tries to impress another person or the world at large; arouses strong, nonreciprocal emotions in others; or has a concern with reputation and prestige. Once the presence of power motivation is determined, the following additional subcategories can be scored: prestige of actor, stated need for power, instrumental activity, block in the world, goal anticipation, goal states, and effect on others. The scorer had previously exceeded $90 \%$ interrater agreement on calibration materials that were prescored by an expert and which are contained in the manual and in Smith (1992). On average, participants wrote $424(S D=124)$ words, containing $9.26(S D=5.83)$ motive scores summed across all five stories. Motive scores were positively correlated with protocol length $(r=.66)$, and we therefore corrected them for protocol length by regression and converted the residuals to $z$ scores. The converted power motive scores did not significantly deviate from a normal distribution $(p>.10)$.

Self-reported affect. Participants' affect was assessed with the Hedonic Tone Scale from the University of Wales Mood Adjective Check List (Matthews et al., 1990), which consists of the items happy, satisfied, contented, cheerful, sad, depressed, dissatisfied, and sorry. Items were presented in random order with the primer "Right now I feel. .." and participants could endorse each item on a 4-point scale featuring the gradations definitely not, slightly not, slightly, and definitely. After recoding of negative-affect items, hedonic tone sum scores were calculated for each assessment. Internal consistency of the scale was $\geq .76$ for each assessment.

Implicit learning. On the SRTs presented before, during, and after the contest, participants were required to quickly and accurately respond to asterisks presented sequentially in four different screen positions by pressing one of four response keys mapped to those screen positions. The asterisk never appeared in one position twice in a row. The four screen positions (A, B, C, D) were marked by four continually visible, $1.5-\mathrm{cm}-$ wide underscores, with $2.5 \mathrm{~cm}$ distance between adjacent underscores, spread out horizontally in the middle of the screen. On each trial, response registration started with a 1-cm-wide asterisk appearing above one of the underscores (e.g., _ _ $*_{-}$) and was terminated with a key press. Intertrial intervals (ITI) were $300 \mathrm{~ms}$. Twelve trials made up one sequence, and participants' response times (RT) were averaged per sequence presentation for subsequent analyses, with RTs $>1,500 \mathrm{~ms}$ and response latencies generated by incorrect responses excluded. As a measure of response accuracy, response errors on a given sequence were measured by summing incorrect key presses. Participants worked on two types of sequences during the pre- and postcontest SRTs as well as during the contest: (a) a fixed sequence, in which stimulus presentation positions always had the order DABDCACBADBC, thus featuring a constant pattern of stimulus 
presentations (and corresponding motor responses), which could be learned and therefore used to predict successive stimulus presentations within the sequence, and (b) random sequences, in which stimuli were presented in random order across the four screen positions and thus did not provide any pattern that could be learned. Fixed and random sequences were presented in alternating order, with pre- and postcontest SRTs and each round on the contest always starting with a random sequence. During pre- and postcontest SRTs, participants worked on 26 fixed and 26 random sequences each, and their performance (response errors and response speed) was averaged separately for each sequence type (fixed vs. random) and assessment (prevs. postcontest) for later analyses. Because the resulting four response error scores were not normally distributed, we transformed them using the formula $\log (0.2+$ error score $)$. The log-transformed scores did not differ from a normal distribution $(p s>.10)$.

Implicit learning awareness. On the awareness test, participants were told that the SRT had contained a predictable pattern that they may have become aware of and that they were now required to identify. They then saw both the actual fixed sequence and a distractor sequence (BDACDBABCADC) presented on the screen, with an asterisk presentation time of $500 \mathrm{~ms}$ per position and a 300-ms ITI. Participants did not have to respond to the asterisks. Sequence order (real then distractor, distractor then real) was balanced across participants. After each sequence, participants gave their response to the question "Was this the predictable, fixed sequence?" on a 5-point scale with the gradations definitely not, probably not, not sure, probably, and definitely.

Salivary T measurement. At each sampling point, participants used a fresh sugar-free chewing gum to collect up to $7 \mathrm{~mL}$ saliva in a sterile polypropylene vial (Dabbs, 1991). Vials were closed and frozen immediately at the end of each session. Samples were freed from mucopolysaccharides and other residuals by three freeze-thaw cycles with subsequent centrifugation. Some samples did not have enough volume to assay them, either because participants had not provided enough sample or because of leaks during sample storage. Hence, for T measurements (T1 through T6, respectively), $n \mathrm{~s}=87,87,89,90,89$, and 91 . Salivary $\mathrm{T}$ levels were determined by solid-phase ${ }^{125}$ I radioimmunoassays (Coat-A-Count TKTT, Diagnostic Products Corporation, Los Angeles), using the protocol described by Campbell, Schultheiss, and McClelland (1999) with a 24-hr preincubation at room temperature. Unknown sample concentrations were estimated from the standard curve using log-logit curve fitting. Analytical recovery for control samples (water-diluted Lyphochek samples from Bio-Rad Laboratories, Hercules, CA) with low (59 pg/mL), medium (125 $\mathrm{pg} / \mathrm{mL})$ and high $(250 \mathrm{pg} / \mathrm{mL}) \mathrm{T}$ concentrations was at $97.31 \%, 100.82 \%$, and $99.07 \%$. Analytical recovery for samples from an in-house male saliva pool $(89 \mathrm{pg} / \mathrm{mL})$ spiked with low and medium Lyphochek control samples was at $97.31 \%$ and $100.82 \%$. Intraassay CV, calculated for participants' samples, was at $4.72 \%$, and interassay $\mathrm{CV}$, averaged across the in-house saliva pool and the low-, medium-, and high-concentration control samples, was at $6.62 \%$. Analytical sensitivity $\left(B_{0}-3 S D\right)$ was at $1 \mathrm{pg} / \mathrm{mL}$.

Suspicion check. Participants received a sheet with the following instruction at the top: "Please describe your experiences with the materials, tests, and questionnaires during this session. What did you observe, what were your impressions?" They were given approximately $5 \mathrm{~min}$ to write down their impressions, which were later coded for whether they reflected any suspicions about the contest procedure. Ten participants (1 loser, 9 winners) mentioned that they suspected the contest outcome to be rigged. Although relative to nonsuspicious participants, suspicious participants showed reduced changes in self-reported affect from before to after the contest, suspicion had no detectable effect on $\mathrm{T}$ changes or implicit learning. Moreover, removing suspicious participants from the analyses reported below left the results virtually unchanged. Therefore, we retained suspicious participants in all analyses.

Statistical procedures. All analyses were conducted with SYSTAT 10 and involved regression and correlation analysis, repeated-measures analysis of variance (ANOVA), analysis of covariance (ANCOVA), and $t$ tests.
Effects predicted based on Schultheiss and Rohde's (2002) study were tested one-tailed in follow-up analyses (i.e., power motive effects on implicit learning and $\mathrm{T}$ changes in winners and losers); all other tests were conducted two-tailed.

\section{Results}

Implicit learning. To determine whether implicit learning had occurred during the contest, we conducted one repeated-measures ANOVA for response speed and one for log-transformed error scores, with measure (fixed vs. random sequence) and time (prevs. postcontest) as within-subject factors. Two significant Measure $\times$ Time effects indicated that men were considerably faster on fixed sequences $(M=311 \mathrm{~ms})$ than on random sequences $(M=$ $330 \mathrm{~ms})$ after the contest, as compared to before the contest $(M \mathrm{~s}=$ 382 and $389 \mathrm{~ms}$, respectively); for the interaction, $F(1,94)=$ $37.15, M S E=84.23, p<.000005$, and also made fewer errors on fixed sequences $(M=-0.35)$ than on random sequences $(M=$ $0.08)$ after the contest, as compared with before the contest $(M \mathrm{~s}=$ -0.62 and -0.25 , respectively); for the interaction, $F(1,940=$ $6.47, M S E=0.048, p=.01$. We interpreted the postcontest performance advantage on fixed sequences as an indication that participants had indeed learned the fixed visuomotor sequence.

To test whether implicit learning gains could be accounted for by our predictors, we created difference scores (random minus fixed sequences) for postcontest speed and accuracy that code for the magnitude of each participant's learning gain, with higher scores on either measure reflecting better learning (cf. Schultheiss et al., in press). Implicit learning speed and accuracy scores were positively correlated $(r=.50, p<.00000005)$, which suggests that implicit learning effects in either variable could not be accounted for by speed-accuracy trade-offs. We subjected these scores to regression analyses with condition, power motive, and their interaction term as predictors. Although neither main nor interaction effects became significant for the speed-based index of implicit learning, we obtained a significant Condition $\times$ Power Motive effect for the accuracy index, $B=0.198, S E=.077$, $t(91)=2.56, p=.01$. As shown in Figure 1 and Table 1 , this

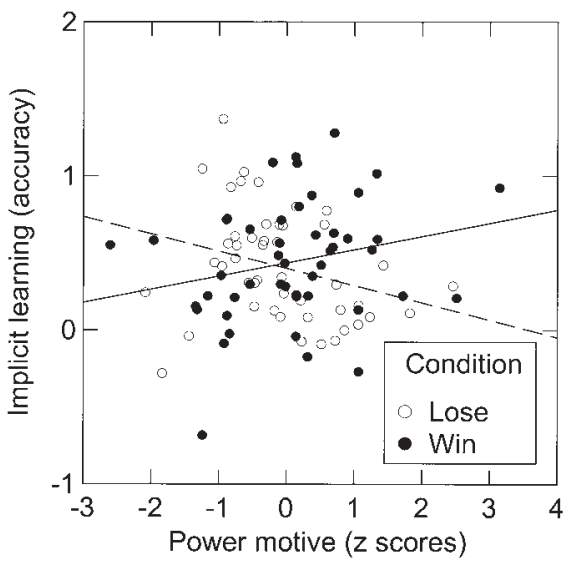

Figure 1. Implicit learning accuracy (log-transformed errors on postcontest random sequences minus log-transformed errors on postcontest fixed sequences) as a function of contest outcome and implicit power motivation in men. Solid line: winners, dashed line: losers (Study 1). 
Table 1

Effects of Contest Outcome and Power Motivation on Dependent Variables, Study 1

\begin{tabular}{|c|c|c|c|c|c|c|c|c|c|c|c|c|}
\hline \multirow[b]{2}{*}{ Variable } & \multicolumn{3}{|c|}{ Winners } & \multicolumn{3}{|c|}{ Losers } & \multirow[b]{2}{*}{$p$} & \multirow[b]{2}{*}{1} & \multirow[b]{2}{*}{2} & \multirow[b]{2}{*}{3} & \multirow[b]{2}{*}{4} & \multirow[b]{2}{*}{5} \\
\hline & $M$ & $S D$ & $n$ & $M$ & $S D$ & $n$ & & & & & & \\
\hline 1. Power motive ( $z$ scores) & 0.09 & 1.08 & 48 & -0.09 & 0.91 & 47 & $n s$ & - & $.21 \dagger$ & $.24 \dagger \dagger$ & .09 & .03 \\
\hline 2. $\Delta$ Testosterone $(\mathrm{pg} / \mathrm{mL})$ & -1.98 & 13.80 & 41 & 1.77 & 14.54 & 46 & $n s$ & $-.38 \dagger \dagger \dagger$ & - & .03 & -.21 & .01 \\
\hline 3. Implicit learning (accuracy) & 0.44 & 0.39 & 48 & 0.41 & 0.36 & 47 & ns & $-.29 \dagger \dagger$ & $.39 * *$ & - & .23 & -.24 \\
\hline 4. $\Delta$ Hedonic tone (T1) & 3.06 & 2.60 & 48 & -3.07 & 4.08 & 47 & $<.000001$ & .22 & -.07 & -.15 & - & $.49^{* *}$ \\
\hline 5. $\Delta$ Hedonic tone (T2) & 0.88 & 2.76 & 48 & -0.84 & 3.13 & 47 & $<.01$ & .16 & -.11 & -.15 & $.61 * *$ & - \\
\hline
\end{tabular}

Note. Winners are above and losers are below the diagonal. $\Delta$ Testosterone: testosterone 15 -min postcontest, residualized for precontest testosterone; $\Delta$ Hedonic tone (T1): hedonic tone immediately after the contest, residualized for precontest hedonic tone; $\Delta$ Hedonic tone (T2): hedonic tone 15 -min postcontest, residualized for precontest hedonic tone.

$\dagger p<.10$, one-tailed. $\dagger \dagger p<.05$, one-tailed. $\dagger \dagger \dagger p<.01$, one-tailed. $* * p<.01$, two-tailed.

effect was due to a positive correlation between power motivation and implicit learning accuracy among winners and a negative correlation between these variables among losers. The Condition $\times$ Power Motive effect remained significant $(p s<.05)$ after we controlled for precontest implicit learning accuracy and also after we replaced the postcontest difference score with logtransformed error scores on postcontest fixed sequences as the dependent variable and partialed out log-transformed error scores on postcontest random sequences.

On the subsequent awareness test, participants were slightly more certain that the fixed sequence was "fixed" $(M=3.04)$ than the random sequence $(M=2.78), p=.06$. When we created a sequence-awareness variable by subtracting participants' recognition scores on the random sequence from their recognition scores on the fixed sequence and converted these to $z$ scores, we found this measure to have no significant overlap with postcontest implicit learning accuracy $(r=-.09)$ or speed $(r=-.12, p \mathrm{~s}>.10)$. Moreover, when we included sequence awareness as a predictor in the regression analyses described above, this variable failed to predict implicit learning accuracy as a main effect or as a term in two- or three-way interactions with the other predictors, whereas the Condition $\times$ Power Motive effect remained significant $(p<$ $.05)$. For the implicit learning speed index, none of the main and interaction terms involving sequence awareness approached significance. Thus, what little awareness men had of the fixed sequence presented in the implicit learning task did not account for the magnitude of their learning gains or the conjoint effects of contest outcome and power motive on implicit learning accuracy.

Salivary T. Men's average salivary T levels (in $\mathrm{pg} / \mathrm{mL}$, standard deviations in parentheses) were 125 (46), 122 (46), 122 (47), 120 (43), 121 (45), and 118 (42) from T1 through T6, respectively, and thus within the typical range of young male adults' salivary $\mathrm{T}$ (cf. Dabbs et al., 1995; Schultheiss et al., 2003). After controlling for time of day, which was negatively correlated with T at T1 ( $r=$ $-.23, p<.05)$, men's power motive did not significantly predict $\mathrm{T}$ at session start (T1). However, the interaction between time of day and power motive reached the level of a trend $(B=-3.42$, $S E=2.02, p<.10)$. Follow-up analyses indicated that, whereas power motivation and $\mathrm{T}$ were positively associated before 1 p.m., $r(28)=.40, p<.05$, they were not after 1 p.m., $r(58)=-.14, n s$. Next, using a repeated-measures ANCOVA with T at T1 as covariate, we tested whether power motivation had an effect on changes in $\mathrm{T}$ after the contest instruction (T2) or after the goal imagery exercise (T3), but without significant results. To examine effects of condition and power motivation on men's $\mathrm{T}$ after the contest, we ran a repeated-measures ANCOVA with T at T4, T5, and T6 as within-subjects factor and precontest T (T3) as a covariate. $^{2}$ Although main effects of power motive and condition were not significant, we found a significant Power Motive $\times$ Condition $\times$ Time effect, $F(2,162)=3.48, M S E=131.76, p<$ .05. Further ANCOVA analyses indicated that the Power Motive $\times$ Condition effect was not significant for $\mathrm{T}$ at $\mathrm{T} 4$ or T6 (i.e., 0 or 30 min postcontest), but was highly significant for T at T5 (15 min after the contest), $B=9.00, S E=3.04, t(82)=2.96, p<$ .005. As Figure 2 and Table 1 show, this effect was based on a significant negative correlation between power motive and $\mathrm{T}$ (residualized change scores) among losers and a marginally significant positive correlation between these variables among winners.

Self-reported affect. To examine effects of condition and power motivation on participants' hedonic tone after the contest, we ran a repeated-measures ANCOVA with hedonic tone at $0 \mathrm{~min}$, $15 \mathrm{~min}$, and $30 \mathrm{~min}$ postcontest as within-subject factor and precontest hedonic tone as a covariate. We found a highly significant Condition $\times$ Time effect, $F(2,184)=45.94, M S E=4.78$, $p<.000005$, which reflected the fact that winners and losers showed the strongest differences in their affective response to the contest immediately after the contest, somewhat weaker differences $15 \mathrm{~min}$ postcontest, and no significant differences $30 \mathrm{~min}$ postcontest, when their hedonic tone had returned to the precontest baseline (cf. Table 1). Condition $\times$ Power Motive and Condition $\times$ Power Motive $\times$ Time effects were not significant. Thus, men's subjective satisfaction or dissatisfaction with the contest outcome depended strongly on whether they had won or lost the contest and how much time had elapsed since the end of the contest, but it did not depend on their implicit power motive levels.

Mediation analyses. Following Schultheiss and Rohde's (2002) observation of a positive correlation between postcontest $\mathrm{T}$ increases and implicit learning in men, we first examined whether

\footnotetext{
${ }^{2}$ In this study and the second, the correlations of postcontest $\mathrm{T}$ levels with $\mathrm{T}$ at $\mathrm{T} 3$ were considerably higher than those with $\mathrm{T}$ at $\mathrm{T} 1$ or $\mathrm{T} 2$. Thus, consistent with the common practice in psychophysiological research to use baseline measures recorded in close temporal proximity to the response of interest and thus to control a maximum of variance (e.g., Fridlund \& Cacioppo, 1986), we used $\mathrm{T}$ at $\mathrm{T} 3$ as a covariate in these analyses.
} 


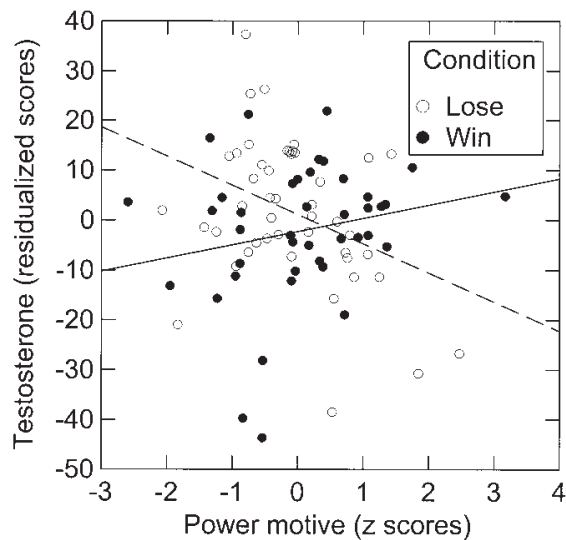

Figure 2. Salivary testosterone $15 \mathrm{~min}$ postcontest (residualized for precontest salivary testosterone levels; in $\mathrm{pg} / \mathrm{mL}$ ) as a function of contest outcome and implicit power motivation in men. Solid line: winners, dashed line: losers (Study 1).

there was any indication of such a link in our present sample. In the overall sample, we found $\mathrm{T}$ increases $15 \mathrm{~min}$ postcontest to be positively associated with enhanced implicit learning by the accuracy criterion, $r(87)=.22, p<.05$, but not by the speed criterion, $r(87)=.05, n s$. As Table 1 shows, among losers, increases in $\mathrm{T}$ at T5 were significantly associated with higher learning gains, whereas neither variable was significantly associated with changes in hedonic tone immediately postcontest (T1) or $15 \mathrm{~min}$ postcontest (T2). In contrast, among winners $\mathrm{T}$ changes and implicit learning were not significantly associated with each other or with hedonic tone changes. Because T changes (T5), implicit learning (accuracy), and power motivation all showed substantial correlations among losers, we next tested whether in this subsample the power motivation $\rightarrow$ implicit learning effect would still be significant after controlling for residualized $\mathrm{T}$ change scores at $\mathrm{T} 5$. The power motivation $\rightarrow$ implicit learning effect was reduced from $B=-0.104, S E=0.052, p<.05$, when tested without controlling for T changes, to $B=-0.060, S E=0.054, p>.20$, when tested controlling for $\mathrm{T}$ changes. The $\mathrm{T}$ variable remained a significant positive predictor of implicit learning in this regression, $B=$ 0.0074, $S E=0.0034, p<.05$. Conversely, when we tested the power motivation $\rightarrow \mathrm{T}$ (T5) effect with $\mathrm{T}$ at $\mathrm{T} 3$ covaried out and controlling for implicit learning, the power motive retained its significant influence on T, $B=-5.91, S E=2.22, p=.01$. These analyses suggest, then, that among losers the negative effect of power motivation on implicit learning was mediated by reduced $\mathrm{T}$ levels.

\section{Discussion}

As hypothesized, we found that implicit power motivation enhanced implicit learning and $\mathrm{T}$ increases $15 \mathrm{~min}$ after the contest in winners and impaired implicit learning and $\mathrm{T}$ decreases $15 \mathrm{~min}$ after the contest in losers. Moreover, the effects of implicit power motivation on implicit learning among losers were statistically mediated by decreased $\mathrm{T}$ levels, whereas in winners, the comparatively weaker effect of power motivation on postcontest $\mathrm{T}$ may have prevented the detection of such a T-learning link. These findings parallel those reported by Schultheiss and Rohde (2002) in that they document (a) a positive effect of power motivation on $\mathrm{T}$ in winners and a negative effect in losers and (b) a link between $\mathrm{T}$ and implicit learning. They thus provide mounting evidence that $\mathrm{T}$ is involved in reinforcement processes in men.

Our findings go beyond Schultheiss and Rohde's (2002) study by showing that the aspect of implicit learning most sensitive to the conjoint influence of implicit power motivation and social victory or defeat is the accuracy with which a behavior that, from the participant's perspective, was instrumental for winning (or losing) the contest is learned. By comparison, sequence-execution speed was not noticeably affected by either the contest outcome or participants' power motive or by the interaction of these variables.

Our findings differ somewhat from Schultheiss and Rohde's (2002) in that we obtained a strong negative effect of power motivation on $\mathrm{T}$ in losers (they reported a nonsignificant negative effect) and a marginally significant positive effect of power motivation on $\mathrm{T}$ in winners (they observed a significant positive effect). We suspect that methodological variations may explain the differences. Specifically, Schultheiss and Rohde's winners may have consummated the impact incentive more profoundly than our winners, because they were allowed to actively stop their opponent with a command as soon as they finished a contest round. In contrast, winners in our study passively received feedback after each round from the computer and did not have any opportunity to interrupt their opponent directly. However, the defeat experience may have been more pronounced for losers in our present study, because in contrast to Schultheiss and Rohde's losers, who won a third of all contest rounds, our losers prevailed only on 2 of 10 rounds. We tentatively explain the stronger effect of power motivation on losers' $\mathrm{T}$ in our study with this methodological difference.

Notably, in contrast to implicit learning and $\mathrm{T}$ changes, which were not directly influenced by victory or defeat, self-reported affect after the contest was strongly affected by contest outcome, with winners experiencing a marked increase and losers a marked decrease in happiness. However, contrary to the second part of our hedonic-change hypothesis, men's affective responses to the contest were not moderated by their power motive. Interestingly, changes in self-reported affect also had no overlap with changes in $\mathrm{T}$ and, more important, implicit learning of instrumental behavior, which, in our view, is a straightforward and valid measure of reinforcement.

\section{Study 2}

In Study 2, we used the same procedures as in Study 1, but this time had women compete against each other in the contest. As reviews by Stewart and Chester (1982) and Winter (1988) suggest, the behavioral expression of the power motive is similar in men and women; that is, power-motivated women are just as likely as power-motivated men to express their need for impact in unrestrained, aggressive behaviors. We therefore proceeded on the assumption that power-motivated women would see the dominance contest as an incentive for having impact on another person and be particularly sensitive to succeeding or failing at this task. Thus, we retained the instrumental-learning hypothesis without further qualifications for this study. In contrast, we adopted the weak version of the T-change hypothesis as described in the introduction and expected that women's power motive would 
predict their $\mathrm{T}$ response to the contest without our further specifying the direction of this effect as a function of contest outcome. Finally, on the basis of the results of Study 1, we modified the hedonic-change hypothesis in the following way: We expected contest outcome, but not its interaction with women's power motive, to influence self-reported affect after the contest.

\section{Method}

Participants. From March to November 2002, 86 individuals participated in sessions scheduled between 10:30 a.m. and 6:00 p.m. ${ }^{3}$ Because of fluctuations in the power supply to the testing room, the contest phase was prematurely aborted in five pairs of participants, and their data were therefore discarded. Another participant had to leave immediately after the contest was over, and her data could not be used in the analyses. The women remaining in the sample $(N=75)$ were 20.82 years old on average $(S D=3.10)$ and enrolled as undergraduate and graduate students at the University of Michigan. Thirty-one women reported that they were currently using birth-control pills. Psychology majors were not admitted to the study.

Design and procedure. Design, procedure, and materials were identical with Study 1, except where indicated. Thirty-eight women participated in the winning condition and 37 women participated in the losing condition. Participants used the keys $z, x, n$, and $m$ on the regular computer keyboard to respond to stimuli shown in positions A, B, C, and D on the SRT during the contest and the pre- and postcontest assessments.

Implicit power motive. We replaced trapeze artists with a picture showing a crouching woman with a knife in one hand and bicycle race with a picture of two women competing for the ball in a game of lacrosse. We deemed these pictures to be particularly suitable female cues for aggressive or competitive power motivation. A trained scorer who had previously exceeded $85 \%$ interrater agreement on calibration materials coded all protocols. On average, participants wrote $476(S D=118)$ words, containing $4.45(S D=2.97)$ motive scores summed across all five stories. The distribution of motive scores was skewed (Kolmogorov-Smirnoff test, $p<$ $.01)$, and we therefore transformed them with the formula square root $(1+$ motive score). The transformed motive scores were positively correlated with protocol length $(r=.39)$, and we corrected them for protocol length by regression and converted the residuals to $z$ scores. The converted power motive scores did not significantly deviate from a normal distribution, $p>.10$.

Self-reported affect. Internal consistency of the hedonic tone scale was $\geq .85$ for each assessment.

Implicit learning. With the exception of precontest fixed sequence error scores, which did not fully conform to a normal distribution $(p<$ $.05)$, response error scores did not significantly differ from a normal distribution after we had transformed them with the formula $\log (0.5+$ error score), $p \mathrm{~s}>.10$.

Salivary T measurement. Some samples did not have enough volume, either because participants had not provided enough sample or because of leaks during sample storage. Hence, for T measurements (T1 through T6) $n \mathrm{~s}=71,75,74,75,75$, and 74, respectively. Analytical recovery for control samples (water-diluted Lyphochek samples) with medium (30 $\mathrm{pg} / \mathrm{mL})$ and high $(63 \mathrm{pg} / \mathrm{mL}) \mathrm{T}$ concentrations was at $91.57 \%$ and $90.09 \%$. Intraassay CV, calculated for participants' samples, was at $8.53 \%$, and interassay $\mathrm{CV}$, averaged across a female in-house saliva pool $(16 \mathrm{pg} / \mathrm{mL})$ and the medium- and high-concentration control samples, was at $7.79 \%$. Analytical sensitivity $\left(B_{0}-3 S D\right)$ was at $2.58 \mathrm{pg} / \mathrm{mL}$.

Suspicion check. Seven participants (3 losers, 4 winners) suspected the contest outcome to be rigged. Again, suspicious participants showed reduced changes in self-reported affect from before to after the contest, but suspicion had no detectable effect on $\mathrm{T}$ changes or implicit learning. Moreover, removing suspicious participants from the analyses reported below left the results virtually unchanged. Therefore, we retained suspicious participants in all analyses.

Statistical procedures. The predicted effects of power motive on implicit learning among winners and losers were tested one-tailed; all other tests were conducted two-tailed.

\section{Results}

Implicit learning. Women demonstrated implicit learning through being faster on fixed $(M=339 \mathrm{~ms})$ than on random sequences $(M=356 \mathrm{~ms})$ after the contest, as compared with before the contest $(M \mathrm{~s}=417$ and $419 \mathrm{~ms}$, respectively); for the interaction, $F(1,73)=59.80, M S E=71.28, p<.000005$, and making fewer errors on fixed $(M=0.11)$ than on random sequences $(M=0.35)$ after the contest, as compared with before the contest $(M \mathrm{~s}=-0.04$ and 0.08 , respectively); for the interaction, $F(1,74)=15.29, M S E=0.018, p<.0005$.

As in Study 1, we next created difference scores for postcontest speed and accuracy and subjected these scores to regression analyses with condition, power motive, and their interaction term as predictors. For the speed index, we found a significant main effect of condition (cf. Table 2), which indicated that winners showed generally better learning by the speed criterion than losers. Although the Power Motive $\times$ Condition effect on sequenceexecution speed was not significant, we observed a marginally significant negative correlation between the power motive and the speed index in losers. For sequence-execution accuracy, we obtained a significant Condition $\times$ Power Motive effect, $B=0.136$, $S E=0.056, t(71)=2.44, p<.05$. As shown in Table 2 and Figure 3, this effect was due to a positive correlation between power motive and implicit learning accuracy among winners and a negative correlation between these variables among losers. The Condition $\times$ Power Motive effect remained significant $(p s \leq .05)$ after we controlled for precontest implicit learning accuracy and also after we replaced the postcontest difference score with logtransformed error scores on postcontest fixed sequences as the dependent variable and partialed out log-transformed error scores on postcontest random sequences.

On the subsequent awareness test, women were no more likely to identify the fixed sequence as "fixed" $(M=2.68)$ than the random sequence $(M=2.51), p>.20$. Following the procedure outlined in Study 1, we also created a sequence-awareness variable and examined its correlations with the two implicit learning indices. Sequence awareness was not significantly associated with implicit learning accuracy $(r=-.00)$, but showed a marginal

\footnotetext{
${ }^{3}$ Men's, but not women's, T levels change slightly with the seasons in humans living in high latitudes, with high $\mathrm{T}$ levels being observed in fall and low $\mathrm{T}$ levels being observed in spring (Moffat \& Hampson, 2000). Although we are not aware of any studies that directly test or document an effect of season on T-driven aggression and dominance in humans, we suggest that seasonality effects cannot be strong or account for the differences between male and female $\mathrm{T}$ responses in the present research, as within-subject seasonal $\mathrm{T}$ fluctuations are not greater than circadian withinsubjects fluctuations, and time of day was not a significant moderator of the results reported here. Moreover, Schultheiss et al. (1999) and Schultheiss and Rohde (2002) reported sizeable T responses to dominance challenges for male participants tested in the low-T seasons spring and summer, indicating that even when basal $\mathrm{T}$ is low, $\mathrm{T}$ reactivity to dominance stimuli is preserved.
} 
Table 2

Effects of Contest Outcome and Power Motivation on Dependent Variables, Study 2

\begin{tabular}{|c|c|c|c|c|c|c|c|c|c|c|c|c|}
\hline \multirow[b]{2}{*}{ Variable } & \multicolumn{3}{|c|}{ Winners } & \multicolumn{3}{|c|}{ Losers } & \multirow[b]{2}{*}{$p$} & \multirow[b]{2}{*}{1} & \multirow[b]{2}{*}{2} & \multirow[b]{2}{*}{3} & \multirow[b]{2}{*}{4} & \multirow[b]{2}{*}{5} \\
\hline & $M$ & $S D$ & $n$ & $M$ & $S D$ & $n$ & & & & & & \\
\hline 1. Power motive ( $z$ scores) & 0.01 & 0.97 & 38 & -0.01 & 1.03 & 37 & $n s$ & - & .08 & $.25 \dagger$ & .03 & -.18 \\
\hline 2. $\Delta$ Testosterone $(\mathrm{pg} / \mathrm{mL})$ & -0.13 & 2.36 & 38 & 0.14 & 2.56 & 36 & $n s$ & $.53 * *$ & - & -.12 & $-.37 *$ & .05 \\
\hline 3. Implicit learning (accuracy) & 0.25 & 0.24 & 38 & 0.23 & 0.25 & 37 & $n s$ & $-.31+\dagger$ & -.09 & - & $.35^{*}$ & -.07 \\
\hline 4. Implicit learning (speed in $\mathrm{ms}$ ) & 20.48 & 14.19 & 38 & 12.47 & 17.12 & 37 & $<.05$ & $-.28 \dagger$ & -.21 & $.40^{*}$ & - & .00 \\
\hline 5. $\Delta$ Hedonic tone & 1.16 & 2.80 & 38 & -3.34 & 4.71 & 37 & $<.000005$ & -.17 & -.14 & -.16 & .10 & - \\
\hline
\end{tabular}

Note. Winners are above and losers are below the diagonal. $\Delta$ Testosterone: testosterone immediately after the contest, residualized for precontest testosterone; $\Delta$ Hedonic tone: hedonic tone immediately after the contest, residualized for precontest hedonic tone.

$\dagger p<.10$, one-tailed. $\dagger \dagger p<.05$, one-tailed. $* p<.05$, two-tailed. $* * p<.01$, two-tailed.

negative correlation with implicit learning speed $(r=-.22, p=$ $.06)$. We conclude from these findings that women were not aware of the pattern inherent in the fixed sequence and therefore are unlikely to have used explicit sequence knowledge to produce the pattern of findings presented in Figure 3.

T. Participants' average salivary $\mathrm{T}$ levels (in $\mathrm{pg} / \mathrm{mL}$, standard deviations in parentheses) were 18 (9), 14 (7), 13 (7), 13 (6), 13 (6), and 13 (7) from T1 through T6, respectively. and thus within the typical range of young female adults' salivary T (cf. Dabbs et al., 1995; Schultheiss et al., 2003). Women's baseline (T1) T levels were influenced by time of day $(r=-.37, p=.001)$ and use of birth-control pills (for users, $M=12 \mathrm{pg} / \mathrm{mL}$; for nonusers, $M=23$ $\mathrm{pg} / \mathrm{mL}), t(68)=-6.27, p<.0000005$. After controlling for pill use and time of day, women's power motive was not significantly associated with $\mathrm{T}$ at $\mathrm{T} 1$. We also explored whether the power motive interacted with either time of day or pill use in predicting $\mathrm{T}$ at $\mathrm{T} 1$ and found that for women not taking the pill, as for men in Study 1 , the Power Motive $\times$ Time of Day interaction was marginally significant, $B=-0.821, S E=0.482, t(36)=-1.70$, $p<.10$. Follow-up analyses revealed a nonsignificant positive correlation between power motivation and $\mathrm{T}$ before 2 p.m., $r(16)=.27$, and a nonsignificant negative correlation after 2 p.m., $r(24)=-.29$. The Power Motive $\times$ Time of Day interaction did

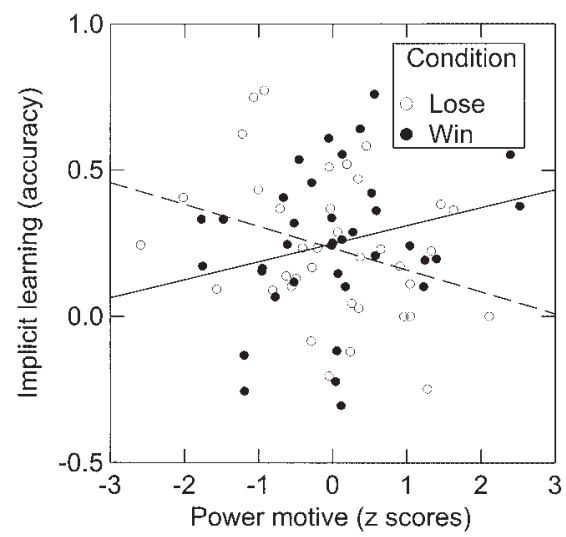

Figure 3. Implicit learning accuracy (log-transformed errors on postcontest random sequences minus log-transformed errors on postcontest fixed sequences) as a function of contest outcome and implicit power motivation in women. Solid line: winners, dashed line: losers (Study 2). not approach significance in women using contraceptive pills. We dropped pill use and time of day from subsequent analyses, because their inclusion as covariates did not substantially alter the results reported below, and their effects were contained in the $\mathrm{T}$ variables we covaried out in these analyses. Using a repeatedmeasures ANCOVA with $\mathrm{T}$ at $\mathrm{T} 1$ as a covariate, we tested whether power motivation had an effect on changes in $\mathrm{T}$ after the contest instruction (T2) or after the goal imagery exercise (T3), but without significant results. To examine effects of condition and power motivation on participants' $\mathrm{T}$ after the contest, we ran a repeatedmeasures ANCOVA with T at T4, T5, and T6 as within-subject factor and precontest T (T3) as a covariate. We found a significant main effect of power motivation on postcontest $\mathrm{T}$ levels, $F(1$, 69) $=6.65, M S E=10.40, p=.01$, that reflected a positive association between the motive measure and averaged postcontest $\mathrm{T}$ levels (controlling for T at T3), $B=0.571, S E=0.220, t(71)=$ $2.60, p=.01(s r=.29)$. This effect remained highly significant $(p<.005)$ even after inclusion of experimental condition and its interaction with power motivation into the repeated-measures ANCOVA. We also obtained a marginally significant Power Motive $\times$ Condition effect, $F(1,68)=3.03, M S E=10.17, p<.10$. Although this effect was not significantly moderated by time, we found the interaction to be significant for $\mathrm{T}$ at $\mathrm{T} 4$, that is, immediately after the contest, $B=-1.13, S E=0.55, t(69)=-2.07$, $p<.05$, but not $15 \mathrm{~min}$ (T5) or $30 \mathrm{~min}$ (T6) after the contest ( $p \mathrm{~s}>$ .20). As Table 2 and Figure 4 show, the Power Motive $\times$ Condition on $\mathrm{T}$ (T4) effect was based on a significant positive correlation between power motive and $\mathrm{T}$ (residualized change scores) in losers and a nonsignificant positive correlation between these variables in winners. Use of birth-control pills did not significantly moderate the power motive main effect or the Power Motive $\times$ Condition effect on postcontest $\mathrm{T}(p \mathrm{~s}>.20)$.

Self-reported affect. Repeating the ANCOVA described in Study 1 , we found a highly significant Condition $\times$ Time effect, $F(2,144)=16.35, M S E=5.89, p<.000005$, which reflected the fact that winners and losers showed strong differences in their affective response to the contest immediately after the contest (cf. Table 2), but not $15 \mathrm{~min}$ or $30 \mathrm{~min}$ postcontest, when their hedonic tone had returned to precontest levels. Condition $\times$ Power Motive and Condition $\times$ Power Motive $\times$ Time effects were not significant. Thus, contest outcome affected women's subjective satisfaction or dissatisfaction immediately after the contest, but not at later 


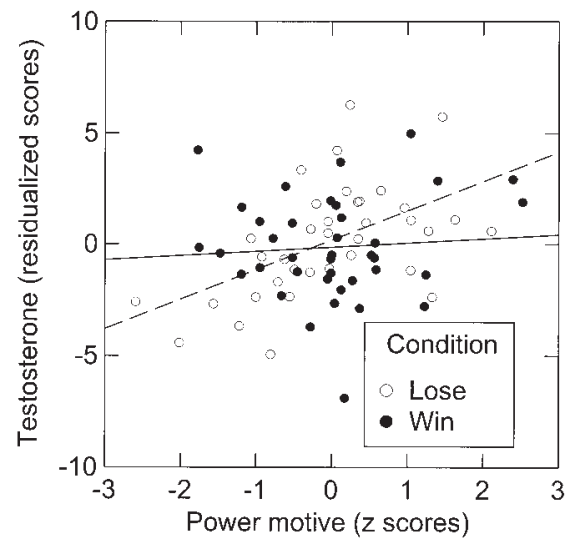

Figure 4. Salivary testosterone immediately after the contest (residualized for precontest salivary testosterone levels; in $\mathrm{pg} / \mathrm{mL}$ ) as a function of contest outcome and implicit power motivation in women. Solid line: winners, dashed line: losers (Study 2).

assessments. Power motivation did not play a role in women's affective responses.

Additional analyses. We examined whether dependent variables that were significantly affected by condition or Condition $\times$ Power Motive effects showed any substantial overlap among winners or losers. As Table 2 shows, T changes from T3 to T4 were not substantially related to implicit learning accuracy among either winners or losers, thus ruling out $\mathrm{T}$ as a mediator of the power motive $\rightarrow$ implicit learning (accuracy) effect. Notably, however, there was some evidence for a negative relationship between $\mathrm{T}$ changes and sequence-execution speed in both winners and losers, $r(74)=-.29, p=.01$, for the full sample. Sequence-execution speed and accuracy scores were positively related among both winners and losers, suggesting that implicit learning effects in either variable cannot be accounted for by speed-accuracy trade-offs.

\section{Discussion}

Again, as hypothesized, power-motivated individuals showed better implicit learning of behavior that had been instrumental for winning the contest and worse implicit learning for behavior that had been "instrumental" for losing the contest. As in Study 1, this effect was obtained only for the accuracy, but not for the speed, with which participants executed the learned visuomotor pattern. As expected, we also found women's power motive to influence their $\mathrm{T}$ responses to the contest outcome, but this effect differed from the findings obtained for men in two important ways: First, power-motivated women generally responded to the contest situation with a $\mathrm{T}$ increase. Second, this increase was considerably stronger in losers than in winners, especially immediately after the contest was over. Because we were unable to find any evidence that $\mathrm{T}$ increases were associated with enhanced learning, $\mathrm{T}$ 's role in female power motivation may not be related to reinforcement, but to priming further aggressive-competitive behavior, particularly after a power goal has been frustrated. On the basis of this hypothesis, we would expect that power-motivated women whose desire for impact has been thwarted will be particularly likely to assert themselves subsequently.
As in Study 1, self-reported affect after the contest was strongly influenced by contest outcome. Winners felt happy and losers felt unhappy immediately after the contest, but these responses to the contest were not moderated by women's power motive. Also similar to Study 1, postcontest affect changes showed no overlap with either $\mathrm{T}$ changes or implicit learning.

\section{Meta-Analysis of Studies 1 and 2}

To evaluate the robustness of the effects of power motivation and contest outcome on implicit learning, we conducted a metaanalysis based on primary data by transforming power motive and implicit learning accuracy scores to $z$ scores within the male and female samples and then combining the samples $(N=170)$. The Condition $\times$ Power Motive on Implicit Learning (accuracy) effect was highly significant in the combined sample, $B=0.541, S E=$ $0.151, t(166)=3.59, p<.0005$, but not moderated by gender ( $p>.90$ for the three-way interaction). Power motive and implicit learning accuracy were significantly positively correlated among winners, $r(86)=.240, p<.05$, and significantly negatively correlated among losers, $r(84)=-.297, p<.01$. Thus, regardless of gender, higher power motivation predicted enhanced implicit learning in winners and impaired implicit learning in losers.

In a second analysis, we tested for the conjoint effect of power motivation, contest outcome, and gender on T at T4 and T5 (i.e., the time window within which we had obtained significant results in both studies) with $\mathrm{T}$ at $\mathrm{T} 3$ held constant. T levels were converted to $z$ scores within each sample. The three-way interaction of the between-subjects predictors was significant, $F(1,152)=8.75$, $M S E=0.158, p<.005$, and not moderated by the within-subject factor time ( $\mathrm{T}$ at $\mathrm{T} 4$ and T5). Follow-up analyses indicated that whereas men's and women's T responses to a victory did not differ from each other (the main effect of power motivation on averaged postcontest $\mathrm{T}$ was positive but nonsignificant in the combined sample, $B=0.086, S E=0.056, p r=.115, p=.13)$, effects of power motivation on $\mathrm{T}$ responses to a defeat were strongly moderated by gender. In men, the power motive was a significant negative predictor $(B=-0.120, S E=0.043, p r=-.387, p<$ $.01)$, and in women, a significant positive predictor of postcontest $\mathrm{T}(B=0.166, S E=0.041, p r=.571, p<.0005$; for the interaction, $B=0.267, S E=0.060, p<.00005)$. All follow-up tests were conducted two-tailed.

\section{General Discussion}

The results of our research provide support for a core, but hitherto untested, assumption about the implicit power motive, namely, that it selects those behaviors that are instrumental for attaining its key incentive (having impact) and, by the same token, inhibits behaviors that are detrimental to incentive attainment (cf. McClelland, 1987). Both in men (Study 1) and in women (Study 2 ), higher levels of power motivation predicted more accurate execution of a visuomotor sequence after its performance had been associated with a victory over an opponent (a case of having impact) and less accurate execution when its performance had preceded a defeat; that is, when participants not only failed to have impact but also were dominated by their opponents. Women and men did not noticeably differ in these learning outcomes, which suggests, first, that the power motive shapes learning in the same 
way in both genders and, second, that beating an opponent of one's own gender in a competition represents a comparably attractive power incentive, and being beaten by an opponent represents a comparably aversive power disincentive, for both genders. Notably, these learning processes did not depend on participants' conscious intention to learn or awareness of what was being learned. What little insight some individuals had into the existence of the fixed visuomotor sequence (which was embedded in unpredictable random sequences) could not account for the conjoint effects of power motivation and contest outcome on learning (Study 1) or was even associated with impaired sequence-execution speed in Study 2.

We think that it is particularly intriguing that power-motivated winners showed implicit learning of a behavior that bore little resemblance to what at first glance would be considered dominant behavior. The fact that they learned to accurately execute an abstract visuomotor sequence because it had led to a victory in the contest shows that the power motive can be exquisitely flexible when it comes to selecting means that ultimately lead to incentive attainment. Indeed, this flexibility of means-ends relationships is one of the hallmarks of motivation (LeDoux, 2002) and may account for why implicit power motivation often manifests itself in behaviors that are perceived as anything but dominant or aggressive (such as power-motivated individuals' use of illustrative gestures, raised eyebrows, and fluent speech in Schultheiss and Brunstein's, 2002, aforementioned study), but which are functional for bringing the power-motivated person closer to having impact (as reflected in the persuasive impact that power-motivated individuals' behaviors had on judges in Schultheiss and Brunstein's study). This "functionality principle" (Schultheiss \& Brunstein, 2002) is also evident in the observation that power-motivated individuals often end up in high-status positions and make good leaders (McClelland \& Boyatzis, 1982; Winter, 1987), an outcome that in most social groups and cultures cannot easily be achieved by intimidating or bullying others but instead requires considerable social skills (see, for instance, Driskell, Olmstead, \& Salas, 1993; Ridgeway, 1987).

Another notable aspect about our implicit learning findings is the fact that we obtained interaction effects of power motive and contest outcome exclusively for sequence-execution accuracy and not for execution speed. Although our findings are consistent with the results of another study in which we examined reinforcing effects of perceived facial emotions on sequence learning (Schultheiss et al., in press), very little is known about the role of implicit learning accuracy in the context of motivation or about the reasons for the functional dissociation between speed and accuracy observed by us. However, one recent study suggests that sequenceexecution accuracy and speed are subserved by different brain systems. Sommer, Grafman, Clark, and Hallett (1999) found that, compared with normal controls, individuals with Parkinson's disease, which is characterized by a degeneration of the nigrostriatal dopamine system, showed impaired sequence-execution speed but preserved sequence-execution accuracy on a visuomotor sequence similar to the one we used in the present research. In other words, implicit learning as reflected in a speed advantage on fixed sequences over random sequences depends on an intact nigrostriatal dopamine system, but implicit learning as reflected in an accuracy advantage on fixed sequences over random sequences does not. From a motivational psychology point of view, it will be particu- larly interesting to identify which brain systems are involved in learning as reflected in sequence-execution accuracy and to explore their relationships with brain structures subserving reward prediction and instrumental learning, such as the nucleus accumbens (see below).

A third noteworthy aspect of our implicit learning results (and to some extent also the results for $\mathrm{T}$ ) is the observation that all interactions between power motivation and winning were disordinal: Low-power winners showed impaired learning relative to high-power winners, and low-power losers showed enhanced learning relative to high-power losers. Moreover, low-power losers' learning gains appeared to be greater than low-power winners' learning gains. These findings suggest that individuals who write stories devoid of power motive imagery in response to pictorial power cues are not indifferent to the power incentive of having impact on others, but may actually fear and avoid it (cf. Schultheiss \& Brunstein, in press, for a similar argument regarding very low achievement motive scores). According to this interpretation, low-power winners showed relatively impaired learning because they were uncomfortable with beating their opponent, whereas low-power losers showed relatively enhanced learning because they had successfully avoided having impact on others. Although speculative, this conjecture is consistent with the early-childhood roots of adult power motivation. As children, low-power individuals, but not high-power individuals, were punished for assertiveaggressive acts against parents, siblings, and friends, and may thus have learned to associate the impact incentive with negative consequences (cf. McClelland \& Pilon, 1983).

Consistent with our T-response hypothesis, we obtained evidence for an effect of the power motive on individuals' $\mathrm{T}$ responses to winning or losing the contest in both men and women. For male U.S. students, the pattern and timing of T changes were remarkably consistent with Schultheiss and Rohde's (2002) findings for German men, with the power motive predicting a $\mathrm{T}$ increase among winners and a $\mathrm{T}$ decrease among losers $15 \mathrm{~min}$ after the contest was over, but not immediately after the contest or $30 \mathrm{~min}$ postcontest. Note that because of the time it takes for steroids to reach maximum levels in salivary fluid, significant differences in men's blood T levels may have occurred about 5 min before we observed the significant, motive-modulated changes 15 min postcontest (cf. Riad-Fahmy, Read, Walker, Walker, \& Griffiths, 1987).

How are such rapid, situation-induced $\mathrm{T}$ changes possible? $\mathrm{T}$ release from the testicles' Leydig cells is normally triggered by pulses of luteinizing hormone (LH) occurring every 1 to $3 \mathrm{hr}$ (Griffin, 2000), which makes LH an unlikely candidate for explaining the rapid $\mathrm{T}$ changes we observed. However, Sapolsky $(1986,1987)$ has demonstrated in his research on social status and reproductive physiology in baboons that other mechanisms are involved in $\mathrm{T}$ secretion besides the LH pathway. He found that the catecholamines epinephrine (E) and NE, which are released by the sympathetic nervous system during stress, have a stimulatory effect on $\mathrm{T}$ secretion within minutes, whereas cortisol released from the adrenals inhibits $\mathrm{T}$ secretion from the testicles just as quickly. Thus, the balance between sympathetic catecholamines and cortisol determines whether $\mathrm{T}$ release is transiently increased or decreased. Sapolsky observed that dominant baboons showed a comparatively strong catecholamine response and weak cortisol response to stress, leading to a $\mathrm{T}$ increase within $30 \mathrm{~min}$, whereas 
low-ranking baboons showed a comparatively weak catecholamine response and strong cortisol response to stress, leading to a rapid decline of $\mathrm{T}$. The existence of the catecholamine pathway to $\mathrm{T}$ release may explain why power-motivated individuals, who have been found to have elevated $\mathrm{E}$ and $\mathrm{NE}$ levels after their need for impact has been aroused (McClelland, 1982; McClelland, Ross, \& Patel, 1985; Steele, 1973), can experience the rapid, victoryinduced $\mathrm{T}$ increases that we and Schultheiss and Rohde (2002) observed in men. Consistent with Sapolsky's (1985) demonstration of an inhibitory effect of cortisol on $\mathrm{T}$ release in nonhuman primates, we have also found that high levels of power motivation predict a significant cortisol increase immediately after losing, but not after winning, a dominance contest (Wirth, Welsh, \& Schultheiss, 2004), which may explain why power-motivated male losers of a contest show a $\mathrm{T}$ decline 15 min postcontest.

What purpose do such rapid, transient postcontest $\mathrm{T}$ changes serve? According to Schultheiss and Rohde (2002; see also Mazur, 1985), postcontest $\mathrm{T}$ changes may modulate the acquisition of instrumental behaviors by directly influencing learning processes. Although highly speculative, this explanation is consistent with their and our observation of a positive association between postcontest $\mathrm{T}$ increases and enhanced implicit learning in men. Thus, power-motivated winners may have shown better learning because elevated levels of T helped to reinforce execution of the visuomotor sequence associated with their victory, and power-motivated losers may have shown impaired learning because of the reduction in rewarding T. Schultheiss and Rohde's (2002) explanation is consistent with the finding that $\mathrm{T}$ augments dopaminergic transmission in the nucleus accumbens, a key structure for reward prediction and reinforcement processes (Frye et al., 2002; Packard, Cornell, \& Alexander, 1997; Packard, Schroeder, \& Alexander, 1998), and its validity could be tested in future studies by, for instance, administering to participants gonadal steroid antagonists (e.g., flutamide), which keep $\mathrm{T}$ and its derivatives from binding to steroid receptors and thus would inhibit T's effect on the accumbens and other structures involved in learning.

Sapolsky (1987) has provided another plausible explanation. T induces rapid increases in muscle anabolism (Tsai \& Sapolsky, 1996) and lowers the threshold for dominance-related aggression mediated by structures of the "emotional brain" (LeDoux, 1996) such as the septum and the amygdala (Albert, Jonik, \& Walsh, 1992). According to Sapolsky, increases in physical strength and aggressiveness associated with high rank or victory make an individual more physically fit and motivated to attain or retain high social rank. T decreases associated with low rank or defeat, in contrast, make an individual less fit for and motivated to engage in further dominance struggles. Thus, because of their postcontest $\mathrm{T}$ increase, power-motivated male winners may have been primed to enter and win further dominance challenges (at least in the short run), whereas power-motivated losers' $\mathrm{T}$ decreases may have kept them from immediately engaging in further, potentially harmful, dominance struggles. Sapolsky's account is consistent with both the priming and the feedback aspects of the T-behavior relationship as outlined by Mazur (1985). However, it is also compatible with Schultheiss and Rohde's (2002) reinforcement account of postcontest $\mathrm{T}$ changes. Animal studies have shown that lesions of the nucleus accumbens lessen T-dependent aggression in male rats (Albert, Petrovic, Walsh, \& Jonik, 1989), which suggests that T's stimulatory effects on aggression have a rewarding component.
None of Sapolsky's (1987), Mazur's (1985), or Schultheiss and Rohde's (2002) explanations for the origin and functions of rapid postcontest $\mathrm{T}$ changes in men seem to account for the contestinduced $\mathrm{T}$ changes we observed in women. Power-motivated women showed a general rise in $\mathrm{T}$ after the contest, but this rise was much more pronounced in losers than in winners, particularly immediately after the contest. Compared with men, women's gonads secrete relatively little $\mathrm{T}$, and the adrenals contribute a comparatively much larger portion to the total levels of circulating androgens (Jones, 1997). We are not aware of any comprehensive model of the physiological correlates of female dominance encounters that-like Sapolsky's (1987) model for T in maleswould explain the causes and functions of the rapid $\mathrm{T}$ changes we observed in women after the contest. It is possible, however, that these changes may reflect activity in the stress axis. Activation of the adrenals by the adrenocorticotrope hormone released from the pituitary increases not only adrenal secretion of the stress hormone cortisol but also of $\mathrm{T}$ precursors, which are partly converted to $\mathrm{T}$ in the body's tissues (e.g., Scott, Svec, \& Dinan, 2000). We therefore speculate that whereas stress axis activation after a defeat may contribute to the $\mathrm{T}$ decrease we observed in power-motivated men, it may actually represent a significant source of rising $\mathrm{T}$ levels in power-motivated women. Because women may be more sensitive to even slight changes in T (Sherwin, 1988) and elevated $\mathrm{T}$ facilitates female aggression (Albert et al., 1992), powermotivated losers may have been more primed than winners for subsequent dominance challenges.

In essence, then, we argue that in power-motivated women, like in power-motivated men, $\mathrm{T}$ serves a priming function and that, due to sex differences in physiological systems, this effect was particularly evident after women had lost a contest. Consistent with such a priming function, we also observed that higher levels of power motivation were associated with higher levels of morning $\mathrm{T}$ in both men and normally cycling women (see also Schultheiss et al., 2003). Unlike in men, however, $\mathrm{T}$ does not seem to serve a reinforcing function in women. Although the effects of contest outcome and power motivation on implicit learning in women were highly similar to those in men, we found no evidence in women for a reinforcing effect of $\mathrm{T}$ increases on implicit learning by the accuracy criterion and, in fact, observed a negative effect on implicit learning by the speed criterion. Notably, findings demonstrating an effect of $\mathrm{T}$ on brain sites involved in reward and reinforcement (e.g., the accumbens) come almost exclusively from the study of male subjects in animal experiments, too (cf. Frye et al., 2002; Packard et al., 1997, 1998).

Finally, consistent with the first part of our hedonic-response hypothesis, we recorded strong affective reactions to the contest outcome in both men and women immediately after the contest. Participants registered elevated happiness and satisfaction immediately after a victory, but they experienced considerable dissatisfaction and depressed mood right after a defeat. Combined with the low rates of suspicion in both studies, these findings attest to the validity of the contest paradigm we used in our research. Yet why were participants' affective responses to the contest outcome not influenced by their implicit power motive, as we had predicted on the basis of Brunstein et al.'s (1998) earlier work? We suggest that differences in the psychology of the testing situation and in methodology may account for the discrepancy between Brunstein et al.'s and our own present findings. In our research, we created a 
highly salient and valenced situational outcome (victory or defeat) that may have activated "feeling rules" in participants. As a consequence, they may have inferred from the situation how they felt (e.g., "You are happy when you win a competition," "You are dissatisfied when you lose a competition") rather than reading out and reporting their core affective state (cf. T. D. Wilson, 2002; T. D. Wilson, Lindsey, \& Schooler, 2000). In contrast, Brunstein et al. (1998) did not experimentally induce emotionally charged events but instead measured individuals' commitment to and gradual attainment of personal goals. Also, they assessed participants' daily mood for up to 2 weeks and then created an aggregate measure of emotional well-being from these assessments. Importantly, their participants reported their mood at fixed times of the day, and thus not necessarily immediately after emotionally arousing situations. This data collection strategy may have helped Brunstein et al. (1998) detect effects of need satisfaction and frustration on individuals' well-being precisely because through the timing and aggregation of mood measurements they were able to peel away much of the mood variance that was due to feeling rules and other cognitively inferred emotional responses and to lay bare a motive-driven undercurrent of core affective states.

We point out that, as our own findings suggest, conscious experience of pleasure or displeasure is not a necessary corollary of reward and reinforcement. In neither study did we find any evidence that postcontest changes in participants' subjective satisfaction or dissatisfaction were substantially related to their learning gains or $\mathrm{T}$ changes. Although we do not rule out that, as Brunstein et al. (1998) have shown, subjective pleasure can accompany the satisfaction of an implicit motivational need, it is not necessary to endow a motivationally significant event, such as victory or defeat, with the capacity to reinforce behavior. As our findings suggest, motivationally driven processes of reward and reinforcement can occur completely outside of a person's conscious awareness and without representation in her or his phenomenological affective experience (see Berridge, 1996; Zajonc, 1980, for related arguments).

To sum up, our present research shows that the implicit power motive in conjunction with power-relevant situational outcomes shapes nonconscious instrumental learning in the same way and $\mathrm{T}$ responses in different ways in men and women, whereas selfreports of pleasure or displeasure over the contest outcome depended on the outcome exclusively and were unrelated to participants' power motive, learning gains, or T changes. Our findings provide considerable support for the hitherto untested notion that implicit motives guide the acquisition of behavior by scaling the incentive value of rewarding and aversive events. In the case of men's $\mathrm{T}$ changes, we also present a more likely candidate for a biological reward substrate of the power motive than the transmitter NE McClelland originally proposed for such a role. Our research breaks new ground by documenting for the first time substantial $\mathrm{T}$ responses to a dominance contest in women. To be sure, the origins and functions of these motive-driven hormone changes deserve further scrutiny in future research. To arrive at a better understanding of how motives shape behavior, both adaptive and maladaptive, we think it will be fruitful to broaden the approach we have taken in the present research to the implicit needs for affiliation and achievement and study how these motives, either as dispositions or as experimentally aroused states (cf. Schultheiss, Wirth, \& Stanton, in press), interact with suitable motive-specific rewarding and punishing events to guide the acquisition of behavior.

\section{References}

Albert, D. J., Jonik, R. H., \& Walsh, M. L. (1992). Hormone-dependent aggression in male and female rats: Experiential, hormonal, and neural foundations. Neuroscience and Biobehavioral Reviews, 16, 177-192.

Albert, D. J., Petrovic, D. M., Walsh, M. L., \& Jonik, R. H. (1989). Medial accumbens lesions attenuate testosterone-dependent aggression in male rats. Physiology and Behavior, 46, 625-631.

Banks, T., \& Dabbs, J. M. (1996). Salivary testosterone and cortisol in a delinquent and violent urban subculture. Journal of Social Psychology, 136, 49-56.

Bateup, H. S., Booth, A., Shirtcliff, E. A., \& Granger, D. A. (2002). Testosterone, cortisol, and women's competition. Evolution and Human Behavior, 23, 181-192.

Berridge, K. C. (1996). Food reward: Brain substrates of wanting and liking. Neuroscience and Biobehavioral Reviews, 20, 1-25.

Brunstein, J. C., Schultheiss, O. C., \& Grässmann, R. (1998). Personal goals and emotional well-being: The moderating role of motive dispositions. Journal of Personality and Social Psychology, 75, 494-508.

Campbell, K. L., Schultheiss, O. C., \& McClelland, D. C. (1999). A necessary adjustment of protocol for use of DPC Coat-A-Count total testosterone assay with saliva. Clinical Biochemistry, 32, 83-85.

Curran, T. (1997). Higher-order associative learning in amnesia: Evidence from the serial reaction time task. Journal of Cognitive Neuroscience, 9, 522-533.

Dabbs, J. M., Jr. (1991). Salivary testosterone measurements: Collecting, storing, and mailing saliva samples. Physiology and Behavior, 49, 815817.

Dabbs, J. M., Jr., Alford, E. C., \& Fielden, J. A. (1998). Trial lawyers and testosterone: Blue-collar talent in a white-collar world. Journal of Applied Social Psychology, 28, 84-94.

Dabbs, J. M., Jr., Campbell, B. C., Gladue, B. A., Midgley, A. R., Navarro, M. A., Read, G. F., et al. (1995). Reliability of salivary testosterone measurements: A multicenter evaluation. Clinical Chemistry, 41, 15811584.

Dabbs, J. M., \& Hargrove, M. F. (1997). Age, testosterone, and behavior among female prison inmates. Psychosomatic Medicine, 59, 477-480.

Driskell, J. E., Olmstead, B., \& Salas, E. (1993). Task cues, dominance cues, and influence in task groups. Journal of Applied Psychology, 78, 51-60.

Feeney, J. J., Howard, J. H., Jr., \& Howard, D. V. (2002). Implicit learning of higher order sequences in middle age. Psychology and Aging, 17, 351-355.

Fridlund, A. J., \& Cacioppo, J. T. (1986). Guidelines for human electromyographic research. Psychophysiology, 23, 567-589.

Frye, C. A., Rhodes, M. E., Rosellini, R., \& Svare, B. (2002). The nucleus accumbens as a site of action for rewarding properties of testosterone and its $5 \alpha$-reduced metabolites. Pharmacology, Biochemistry and Behavior, 74, 119-127.

Gladue, B. A., Boechler, M., \& McCaul, K. D. (1989). Hormonal response to competition in human males. Aggressive Behavior, 15, 409-422.

Griffin, J. E. (2000). Male reproductive function. In J. E. Griffin \& S. R. Ojeda (Eds.), Textbook of endocrine physiology (4th ed., pp. 243-264). New York: Oxford University Press.

Hirschowitz, R., \& Nell, V. (1983). The relationship between need for power and the life style of South African journalists. Journal of Social Psychology, 121, 297-304.

Jones, R. E. (1997). Human reproductive biology (2nd ed.). San Diego, CA: Academic Press.

Josephs, R. A., Newman, M. L., Brown, R. P., \& Beer, J. M. (2003). Status, testosterone, and human intellectual performance: Stereotype threat as status concern. Psychological Science, 14, 158-163. 
Klinger, E. (1975). Consequences of commitment to and disengagement from incentives. Psychological Review, 82, 1-25.

Knutson, B. (1996). Facial expressions of emotion influence interpersonal trait inferences. Journal of Nonverbal Behavior, 20, 165-182.

LeDoux, J. E. (1996). The emotional brain. New York: Simon \& Schuster. LeDoux, J. E. (2002). The synaptic self. New York: Viking Press.

Mason, A., \& Blankenship, V. (1987). Power and affiliation motivation, stress, and abuse in intimate relationships. Journal of Personality and Social Psychology, 52, 203-210.

Matthews, G., Jones, D. M., \& Chamberlain, A. G. (1990). Refining the measurement of mood: The UWIST Mood Adjective Checklist. British Journal of Psychology, 81, 17-42.

Mazur, A. (1985). A biosocial model of status in face-to-face primate groups. Social Forces, 64, 377-402.

Mazur, A., \& Booth, A. (1998). Testosterone and dominance in men. Behavioral and Brain Sciences, 21, 353-397.

Mazur, A., Susman, E. J., \& Edelbrock, S. (1997). Sex differences in testosterone response to a video game contest. Evolution and Human Behavior, 18, 317-326.

McCaul, K. D., Gladue, B. A., \& Joppa, M. (1992). Winning, losing, mood, and testosterone. Hormones and Behavior, 26, 486-504.

McClelland, D. C. (1975). Power: The inner experience. New York: Irvington.

McClelland, D. C. (1980). Motive dispositions. The merits of operant and respondent measures. In L. Wheeler (Ed.), Review of personality and social psychology (Vol. 1, pp. 10-41). Beverly Hills, CA: Sage.

McClelland, D. C. (1982). The need for power, sympathetic activation, and illness. Motivation and Emotion, 6, 31-41.

McClelland, D. C. (1987). Human motivation. New York: Cambridge University Press.

McClelland, D. C. (1989). Motivational factors in health and disease. American Psychologist, 44, 675-683.

McClelland, D. C., \& Boyatzis, R. E. (1982). Leadership motive pattern and long-term success in management. Journal of Applied Psychology, 67, 737-743.

McClelland, D. C., Koestner, R., \& Weinberger, J. (1989). How do self-attributed and implicit motives differ? Psychological Review, 96, 690-702.

McClelland, D. C., \& Pilon, D. A. (1983). Sources of adult motives in patterns of parent behavior in early childhood. Journal of Personality and Social Psychology, 44, 564-574.

McClelland, D. C., Ross, G., \& Patel, V. (1985). The effect of an academic examination on salivary norepinephrine and immunoglobulin levels. Journal of Human Stress, 11, 52-59.

McClelland, D. C., \& Steele, R. S. (1972). Motivational workshops. New York: General Learning Press.

McClelland, D. C., \& Watson, R. I. (1973). Power motivation and risktaking behavior. Journal of Personality, 41, 121-139.

Moffat, S. D., \& Hampson, E. (2000). Salivary testosterone concentrations in left-handers: An association with cerebral language lateralization? Neuropsychology, 14, 71-81.

Packard, M. G., Cornell, A. H., \& Alexander, G. M. (1997). Rewarding affective properties of intra-nucleus accumbens injections of testosterone. Behavioral Neuroscience, 111, 219-224.

Packard, M. G., Schroeder, J. P., \& Alexander, G. M. (1998). Expression of testosterone conditioned place preference is blocked by peripheral or intra-accumbens injection of alpha-flupenthixol. Hormones and Behavior, 34, 39-47.

Purifoy, F. E., \& Koopmans, L. H. (1979). Androstenedione, testosterone, and free testosterone concentration in women of various occupations. Social Biology, 26, 179-188.

Rejeski, W. J., Parker, P. E., Gagne, M., \& Koritnik, D. R. (1990). Cardiovascular and testosterone responses to contested dominance in women. Health Psychology, 9, 35-47.
Riad-Fahmy, D., Read, G. F., Walker, R. F., Walker, S. M., \& Griffiths, K. (1987). Determination of ovarian steroid hormone levels in saliva. An overview. Journal of Reproductive Medicine, 32, 254-272.

Ridgeway, C. L. (1987). Nonverbal behavior, dominance, and the basis of status in task groups. American Sociological Review, 52, 683-694.

Rolls, E. T. (1999). The brain and emotion. Oxford, Great Britain: Oxford University Press.

Sapolsky, R. M. (1985). Stress-induced suppression of testicular function in the wild baboon: Role of glucocorticoids. Endocrinology, 116, 22732278.

Sapolsky, R. M. (1986). Stress-induced elevation of testosterone concentration in high ranking baboons: Role of catecholamines. Endocrinology, $118,1630-1635$.

Sapolsky, R. M. (1987). Stress, social status, and reproductive physiology in free-living baboons. In D. Crews (Ed.), Psychobiology and reproductive behavior: An evolutionary perspective (pp. 291-322). Englewood Cliffs, NJ: Prentice-Hall.

Schultheiss, O. C. (2001). An information processing account of implicit motive arousal. In M. L. Maehr \& P. Pintrich (Eds.), Advances in motivation and achievement (Vol. 12, pp. 1-41). Greenwich, CT: JAI Press.

Schultheiss, O. C., \& Brunstein, J. C. (2001). Assessing implicit motives with a research version of the TAT: Picture profiles, gender differences, and relations to other personality measures. Journal of Personality Assessment, 77, 71-86.

Schultheiss, O. C., \& Brunstein, J. C. (2002). Inhibited power motivation and persuasive communication: A lens model analysis. Journal of Personality, $70,553-582$.

Schultheiss, O. C., Campbell, K. L., \& McClelland, D. C. (1999). Implicit power motivation moderates men's testosterone responses to imagined and real dominance success. Hormones and Behavior, 36, 234-241.

Schultheiss, O. C., Dargel, A., \& Rohde, W. (2003). Implicit motives and gonadal steroid hormones: Effects of menstrual cycle phase, oral contraceptive use, and relationship status. Hormones and Behavior, 43, 293-301.

Schultheiss, O. C., Pang, J. S., Torges, C. M., Wirth, M. M., \& Treynor, W. (in press). Perceived facial expressions of emotion as motivational incentives: Evidence from a differential implicit learning paradigm. Emotion.

Schultheiss, O. C., \& Rohde, W. (2002). Implicit power motivation predicts men's testosterone changes and implicit learning in a contest situation. Hormones and Behavior, 41, 195-202.

Schultheiss, O. C., Wirth, M. M., \& Stanton, S. J. (in press). Effects of affiliation and power motivation arousal on salivary progesterone and testosterone. Hormones and Behavior.

Scott, L. V., Svec, F., \& Dinan, T. (2000). A preliminary study of dehydroepiandrosterone response to low-dose ACTH in chronic fatigue syndrome and in healthy subjects. Psychiatry Research, 97, 21-28.

Sherwin, B. B. (1988). A comparative analysis of the role of androgen in human male and female sexual behavior: Behavioral specificity, critical thresholds, and sensitivity. Psychobiology, 16, 416-425.

Smith, C. P. (Ed.). (1992). Motivation and personality: Handbook of thematic content analysis. New York: Cambridge University Press.

Sommer, M., Grafman, J., Clark, K., \& Hallett, M. (1999). Learning in Parkinson's disease: Eyeblink conditioning, declarative learning, and procedural learning. Journal of Neurology, Neurosurgery, and Psychiatry, 67, 27-34.

Steele, R. S. (1973). The physiological concomitants of psychogenic motive arousal in college males. Unpublished dissertation thesis, Harvard University, Boston.

Stewart, A. J., \& Chester, N. L. (1982). Sex differences in human social motives: Achievement, affiliation, and power. In A. J. Stewart (Ed.), Motivation and society: A volume in honor of David C. McClelland (pp. 172-218). San Francisco: Jossey-Bass. 
Tsai, L. W., \& Sapolsky, R. M. (1996). Rapid stimulatory effects of testosterone upon myotubule metabolism and sugar transport, as assessed by silicon microphysiometry. Aggressive Behavior, 22, 357-364. van Honk, J., Tuiten, A., Hermans, E., Putman, P., Koppeschaar, H., Thijssen, J., et al. (2001). A single administration of testosterone induces cardiac accelerative responses to angry faces in healthy young women. Behavioral Neuroscience, 115, 238-242.

Waber, D. P., Marcus, D. J., Forbes, P. W., Bellinger, D. C., Weiler, M. D., Sorensen, L. G., et al. (2003). Motor sequence learning and reading ability: Is poor reading associated with sequencing deficits? Journal of Experimental Child Psychology, 84, 338-354.

Weinberger, J., \& McClelland, D. C. (1990). Cognitive versus traditional motivational models: Irreconcilable or complementary? In E. T. Higgins \& R. M. Sorrentino (Eds.), Handbook of motivation and cognition: Foundations of social behavior (Vol. 2, pp. 562-597). New York: Guilford Press.

Wilson, G. V., \& Kerr, J. H. (1999). Affective responses to success and failure: A study of winning and losing in competitive rugby. Personality and Individual Differences, 27, 85-99.

Wilson, T. D. (2002). Strangers to ourselves: Discovering the adaptive unconscious. Cambridge, MA: Belknap Press.

Wilson, T. D., Lindsey, S., \& Schooler, T. Y. (2000). A model of dual attitudes. Psychological Review, 107, 101-126.
Winter, D. G. (1973). The power motive. New York: Free Press.

Winter, D. G. (1987). Leader appeal, leader performance, and the motive profiles of leaders and followers: A study of American presidents and elections. Journal of Personality and Social Psychology, 52, 196-202.

Winter, D. G. (1988). The power motive in women-and men. Journal of Personality and Social Psychology, 54, 510-519.

Winter, D. G. (1996). Personality: Analysis and interpretation of lives. New York: McGraw-Hill.

Wirth, M. M., Welsh, K., \& Schultheiss, O. C. (2004). Salivary cortisol changes in humans after winning or losing a dominance contest depend on implicit power motivation. Manuscript submitted for publication.

Wortman, C. B., \& Brehm, J. W. (1975). Response to uncontrollable outcomes: An integration of reactance theory and the learned helplessness model. In L. Berkowitz (Ed.), Advances in experimental social psychology (Vol. 8, pp. 277-336). New York: Academic Press.

Zajonc, R. B. (1980). Feeling and thinking. Preferences need no inferences. American Psychologist, 35, 151-175.

Received February 3, 2004

Revision received July 26, 2004

Accepted August 9, 2004 